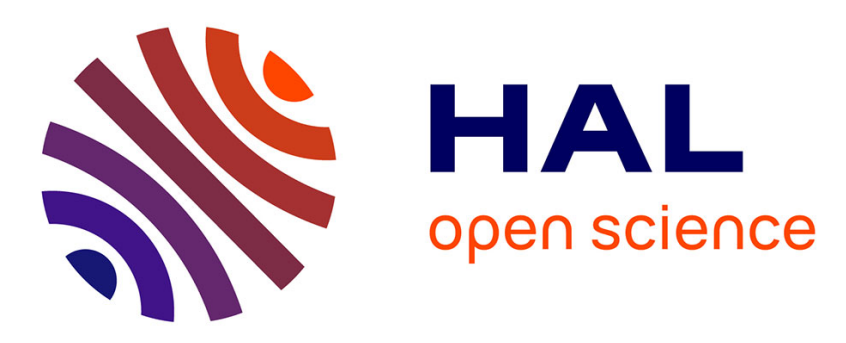

\title{
Nanoscale Metal Phosphide Phase Segregation to Bi/P Core/Shell Structure. Reactivity as a Source of Elemental Phosphorus
}

Lorena Soria, Julian Sklorz, Yannick Coppel, Pierre Roblin, Nicolas Mézailles, Montserrat Gómez

\section{To cite this version:}

Lorena Soria, Julian Sklorz, Yannick Coppel, Pierre Roblin, Nicolas Mézailles, et al.. Nanoscale Metal Phosphide Phase Segregation to Bi/P Core/Shell Structure. Reactivity as a Source of Elemental Phosphorus. Chemistry of Materials, 2020, 32, pp.4213 - 4222. 10.1021/acs.chemmater.0c00478 . hal-03008863

\section{HAL Id: hal-03008863 https://hal.science/hal-03008863}

Submitted on 27 Oct 2021

HAL is a multi-disciplinary open access archive for the deposit and dissemination of scientific research documents, whether they are published or not. The documents may come from teaching and research institutions in France or abroad, or from public or private research centers.
L'archive ouverte pluridisciplinaire HAL, est destinée au dépôt et à la diffusion de documents scientifiques de niveau recherche, publiés ou non, émanant des établissements d'enseignement et de recherche français ou étrangers, des laboratoires publics ou privés. 


\section{Nanoscale Metal Phosphide Phase Segregation}

\section{to $\mathrm{Bi} / \mathrm{P}$ Core/shell Structure. Reactivity as}

\section{Source of Elemental Phosphorus.}

Lorena Soria, ${ }^{\dagger}$ Julian Sklorz, ${ }^{\dagger}$ Yannick Coppel, ${ }^{\S}$ Pierre Roblin, ${ }^{\dagger}$ Nicolas Mézailles ${ }^{\dot{\dagger}^{*}}$ and Montserrat Gómez t* $^{\text {t* }}$

† Laboratoire Hétérochimie Fondamentale et Appliquée (LHFA), Université Toulouse 3 - Paul Sabatier and CNRS UMR 5069, 118 route de Narbonne, 31062 Toulouse Cedex 9, France.

$\S$ CNRS, LCC (Laboratoire de Chimie de Coordination), Université Toulouse 3 - Paul Sabatier, UPS, INPT, 205 route de Narbonne, BP 44099, 31077 Toulouse Cedex 4, France

* Laboratoire de Génie Chimique, Université de Toulouse, CNRS, INPT, UPS, 118 route de Narbonne, 31062 Toulouse Cedex 9, France.

ABSTRACT: We report for the first time the synthesis of well-defined bismuth/phosphorus nanoparticles (Bi/P NPs) based on silyl-halide elimination, by reaction of $\mathrm{BiX}_{3}(\mathrm{X}=\mathrm{I}, \mathrm{Cl})$ and $\mathrm{P}\left(\mathrm{SiMe}_{3}\right)_{3}$ in the presence of different types of stabilizing ligands, such as cinchonidine, 4-(3phenylpropyl)pyridine and polyvinylpyrrolidone. This synthetic approach led to spherical, small and monodisperse nanoparticles (mean diameter $c a$. 2.0-2.5 nm determined by TEM). Wideranging characterization of these nanoparticles including TEM, PXRD and SAXS, and several spectroscopic techniques, like X-ray fluorescence, IR and solid state NMR, proved the formation of a core-shell structure constituted by a crystalline $\mathrm{Bi}(0)$ core and amorphous $\mathrm{P}$ - 
containing shells, representing a unique case of phase segregation for metal/phosphorus materials reported in the literature. The assessed reactivity of the as-prepared Bi/P NPs evidenced their potential application in the synthesis of phosphine $\mathrm{PH}_{3}$ in a safer way than the conventional approach using $\mathrm{P}_{4}$ (white phosphorus) and in a sharp contrast with the reported reactivity of amorphous red phosphorus.

\section{INTRODUCTION}

Bulk metal phosphides $\left(\mathrm{M}_{\mathrm{x}} \mathrm{P}_{\mathrm{y}}\right)$ are nowadays receiving intense attention in the field of materials due to their wide scope of properties and applications in metallurgy and semiconductors for electronics or optics, among others. ${ }^{1-9}$ The structure and composition of these $\mathrm{M}_{\mathrm{x}} \mathrm{P}_{\mathrm{y}}$ binary species have been accurately analyzed for almost all the combinations with metals, except with the heavy elements of group 15 (As, Sb, Bi) ${ }^{10}$ Among them, bismuth phosphide is particularly appealing since it is isoelectronic with $\mathrm{PbS}$, a well-known intrinsic semiconductor used for an extensive range of applications, but exhibiting strong environmental constraints. ${ }^{11-17}$

Concerning its preparation, two synthetic approaches have been reported to obtain $\mathrm{Bi}_{\mathrm{x}} \mathrm{P}_{\mathrm{y}}$. The first methodology relied on the dissolution of phosphorus in molten bismuth, which however did not lead to the desired compound but to the segregation of the elements into their pure form, leading to the synthesis of black and violet allotropes of $\mathrm{P}$, and $\operatorname{Bi}(0){ }^{18,19}$ Based on the successful syntheses of other metal phosphides $\mathrm{M}_{\mathrm{x}} \mathrm{P}_{\mathrm{y}}$ under milder conditions via the formation of $\mathrm{Me}_{3} \mathrm{SiX}(\mathrm{X}=\mathrm{Cl}, \mathrm{Br}, \mathrm{I})$ as concomitant product, we pursued this strategy for the synthesis of $\mathrm{Bi}_{\mathrm{x}} \mathrm{P}_{\mathrm{y} .}{ }^{20}$ Notably, the generation of the strong $\mathrm{Si}-\mathrm{X}$ bond acts as a driving force for the reaction. Following this strategy, Allen et al. reported the formation of an insoluble black material at room temperature from the reaction of $\mathrm{BiCl}_{3}$ with $\mathrm{P}\left(\mathrm{SiMe}_{3}\right)_{3} \cdot{ }^{21} \mathrm{~A}$ range of analyses were carried out to characterize this material, including SEM, EDX, XRD, XPS, thermogravimetric analyses (TGA and DSC) as well as conductivity measurements. These analyses prompted the authors to propose the formation of amorphous hybrid "BiP" materials. However, the characterization of 
the as-prepared materials did not provide unequivocal evidence for the formation of the expected product, whose precise structure remains unknown.

From another standpoint, molecular compounds featuring discrete Bi-P bonds are rather rare. Their synthesis also relies on substitution reactions between reagents containing P-Si (or P-Li) and $\mathrm{Bi}-\mathrm{X}$ bonds. More importantly for the present study, the stability of the Bi-P bond appears to vary in these molecular species. Indeed, Coles and coworkers reported in 2016 that the compound " $\mathrm{Bi}\left(\mathrm{NON}^{\mathrm{R}}\right)\left(\mathrm{PPh}_{2}\right)$ " $\left(\mathrm{NON}^{\mathrm{R}}=\left[\mathrm{O}\left(\mathrm{SiMe}_{2} \mathrm{NR}\right)_{2}\right]\right.$, where $\mathrm{R}=t \mathrm{Bu}$, 2,6-i $\left.\mathrm{Pr}_{2} \mathrm{C}_{6} \mathrm{H}_{3}\right)$ was unstable and readily evolved to form a $\mathrm{P}-\mathrm{P}$ bond $\left(\mathrm{Ph}_{2} \mathrm{P}-\mathrm{PPh}_{2}\right)$ and a $\mathrm{Bi}-\mathrm{Bi}$ bond, whereas the related $\mathrm{Bi}\left(\mathrm{NON}^{\mathrm{R}}\right)\left(\mathrm{PCy}_{2}\right)$ was a stable compound at room temperature. ${ }^{22}$

Between molecules and bulk material domains, nanoparticles may provide a field of interesting and distinctive properties. In this context, the case of "BiP" is particularly appealing for two reasons. Firstly, a fundamental question can be asked: are Bi-P bonds strong enough in nanoalloys vs. Bi-Bi and P-P bonds in the elemental materials? In other words, is "nanoalloyBiP" stable or can phase segregation (hitherto unprecedented) at nanosized scale be observed to form core-shell and/or independent $\mathrm{Bi}$ and $\mathrm{P}$ nanostructures? Furthermore, if "nanoalloy-BiP" is stable enough, the semiconductor nature of bulk BiP shown by Allen and coworkers ${ }^{21}$ should lead to desirable size dependent properties.

In this context and taking into account our experience in the design of nanomaterials, herein we describe the first straightforward synthesis of Bi/P nanoparticles (Bi/P NPs) stabilized by different ligands, together with a full characterization of the as-prepared materials by TEM, XPS, PXRD, SAXS and solid state NMR. These nano-sized materials consist of a $\mathrm{Bi}(0)$ core surrounded by two different P-containing shells, resulting from unprecedented M/P phase segregation in nanoscale metal-phosphorus materials. Preliminary reactivity studies have proved the suitability of these nanomaterials as potential phosphorus atom donors for the controlled synthesis of phosphorus-based derivatives, including $\mathrm{PH}_{3}$. 


\section{RESULTS AND DISCUSSION}

In the last years, we have developed mild synthetic procedures to prepare $\mathrm{M}_{\mathrm{x}} \mathrm{P}_{\mathrm{y}}$ that rely on the use of $\mathrm{P}_{4}$ as stoichiometric $\mathrm{P}$ atom donor. ${ }^{23,24,33,25-32}$ This approach requires appropriate $\mathrm{M}(0)$ precursors, either as monometallic species or nanoparticles. However, for bismuth, zero-valent monometallic species are unknown and even if Bi nanoparticles have been reported, it did not seem the best choice, due to both the high temperature injection (above $90{ }^{\circ} \mathrm{C}$ ) and highly reactive chemicals involved for reducing the corresponding Bi(III) precursors. ${ }^{34-36}$ Thus, we envisaged to prepare Bi/P NPs under smoother conditions in order to control the nanosized $\mathrm{Bi} / \mathrm{P}$ materials, avoiding the formation of bulk materials. ${ }^{20}$ For this purpose, we selected the reaction applied by Allen and coworkers, ${ }^{21}$ relying on $\mathrm{R}_{3} \mathrm{Si}-\mathrm{X}$ elimination as a driving force and using stabilizers to control the growth of nanoparticles in order to prevent precipitation of bulk material (Scheme 1).
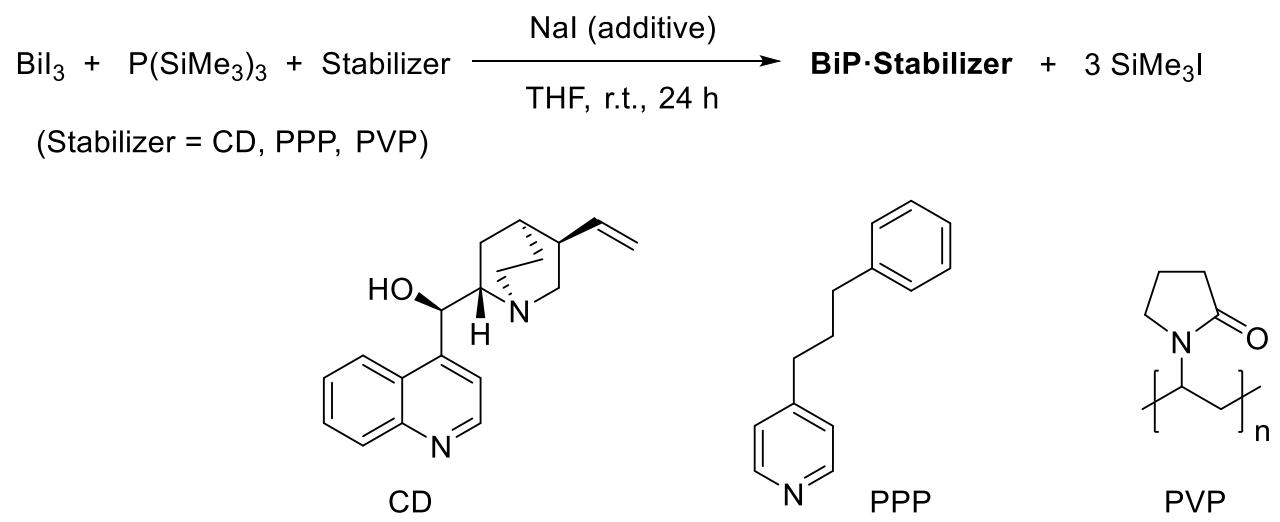

Scheme 1. Synthesis of Bi/P NPs (BiP.Stabilizer) stabilized by different coating agents (CD, PPP, PVP) under optimized conditions.

Pleasingly, the reaction of $\mathrm{BiI}_{3}$ with $\mathrm{P}\left(\mathrm{SiMe}_{3}\right)_{3}$ in $\mathrm{THF}$ at room temperature in the presence of sodium iodide and both molecular (cinchonidine (CD), 4-(3-phenylpropyl)pyridine (PPP)) and polymeric (polyvinylpyrrolidone (PVP)) stabilizers led to black colloidal suspensions of NPs. We have previously proved that ligands such as CD or PPP allow nanoparticles stabilization by coordination at the metal surface, ${ }^{37-41}$ while polymers such as PVP provide steric stabilization 
for nanoparticles of different transition metals. ${ }^{42-45}$ The BiP·Stabilizer materials (BiP.CD, Bi·PPP, BiP·PVP) were isolated as solids by several cycles of centrifugation and washing with THF under $\mathrm{N}_{2}$ atmosphere. TEM analyses showed that BiP.CD and BiP.PPP were constituted of small spherical nanoparticles (ca. 2.3-3.3 nm of mean diameter, Figure 1 and Figure $\mathrm{S} 1$ in the Supporting Information), exhibiting a good dispersion in glycerol in contrast to that observed for BiP.PVP, indicating that the surface stabilization by the polymer was less efficient than in the case involving the ligands $\mathrm{CD}$ and PPP as stabilizers. It is important to highlight that glycerol is crucial to form homogeneous dispersions as previously observed by our group for other metal-based nanoparticles, ${ }^{28,29,32} 41,46$ also permitting TEM analyses of MNPs in glycerol, due to its negligible vapor pressure. On the other hand, the dispersion of Bi/P NPs in dichloromethane exclusively led to the formation of aggregates upon evaporation of the solvent (see Figure S2 in the Supporting Information). 


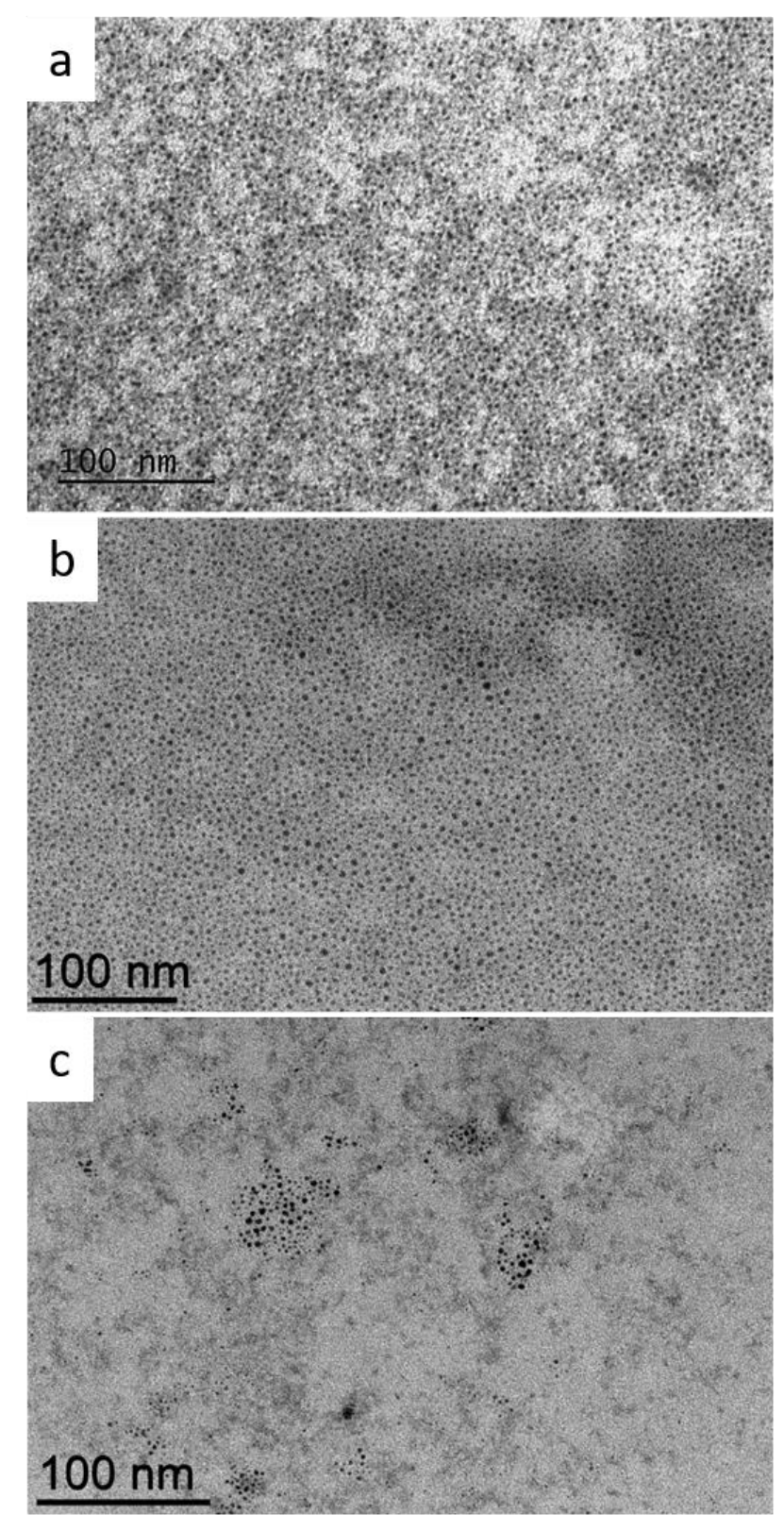

Figure 1. TEM images of Bi/P NPs in glycerol: a) BiP.CD $\left(d_{\text {mean }}=2.3 \pm 0.7 \mathrm{~nm}\right)$, b)

\section{$\mathbf{B i P} \cdot \mathbf{P P P}\left(\mathrm{d}_{\text {mean }}=3.3 \pm 0.9 \mathrm{~nm}\right)$ and c) BiP·PVP}

Optimization of the reaction conditions in order to obtain reproducible materials, revealed that $\mathrm{BiI}_{3}$ is the most suitable precursor due to its higher solubility in THF compared to $\mathrm{BiCl}_{3}$ and $\mathrm{BiBr}_{3}$. Moreover, the addition of $\mathrm{NaI}$ (stoichiometric amount in relation to bismuth salt) to boost the solubility of the metal precursor and an excess of $\mathrm{P}\left(\mathrm{SiMe}_{3}\right)_{3}($ molar ratio $\mathrm{Bi}: \mathrm{P}=1: 2)$ were required to achieve a very efficient consumption of $\mathrm{BiI}_{3}$ (confirmed by XPS and X-ray Fluorescence analyses; see Figures S3 and S4 in the Supporting Information; yield between 63 
and $83 \%$ for BiP.stabilizer, see experimental section). In the absence of NaI, non-homogenous and bigger nanoparticles were observed, even after redispersion in glycerol (see Figure S5 in the Supporting Information). Following a similar approach, but using $\mathrm{BiCl}_{3}$ in the presence of $\mathrm{NaCl}$, nanoparticles together with large aggregates were observed by TEM (see Figure S6 in the Supporting Information). In the absence of stabilizer, no well-defined particles were observed (see Figure S7 in the Supporting Information). Thus, the presence of stabilizers was necessary to afford non-aggregated nanoparticles exhibiting uniform sizes. In the optimization process, different ratios $\mathrm{BiI}_{3}: \mathrm{PVP}$ were tested $(3: 0.5 ; 3: 5 ; 3: 50)$. Final crystalline nanomaterials with well-defined diffraction peaks were obtained only for the 3:0.5 ratio. Based on these results, the same ratio was used with the other stabilizers.

$\mathrm{Bi} / \mathrm{P}$ NPs prepared following the optimized procedure indicated above (Scheme 1), were then characterized by PXRD, XPS, solid state NMR and SAXS. PXRD analyses for the three types of $\mathrm{Bi} / \mathrm{P}$ NPs were consistent with the XRD pattern of the hexagonal structure of $\mathrm{Bi}(0)$, without observing the presence of any crystalline phase of BiP (Figure 2 for BiP. CD; see Figure S8 in the Supporting Information for BiP·PVP and BiP·PPP). The observed peaks were relatively broad, in agreement with the formation of small nanoparticles (mean diameter calculated by Scherrer equation $c a .5 .5 \mathrm{~nm}$ ); therefore, PXRD analysis reveals the exclusive presence of $\operatorname{Bi}(0)$.

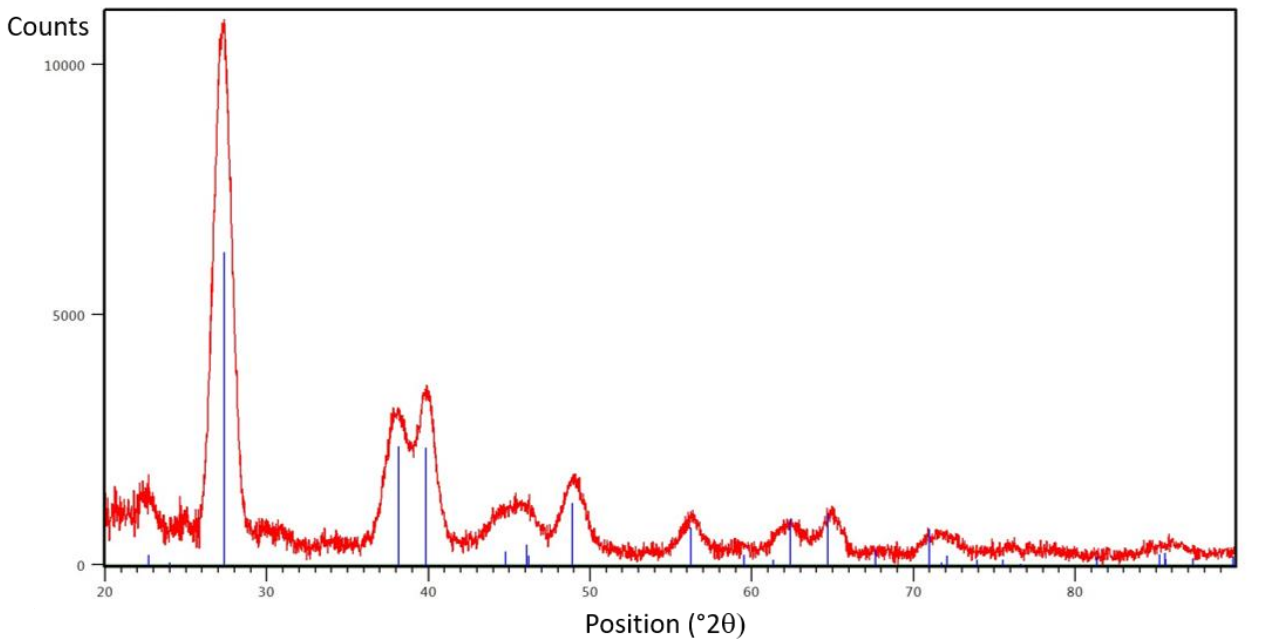


Figure 2. Powder X-Ray diffractogram of BiP.CD. Blue lines indicate the pattern corresponding to the hexagonal structure of bulk $\mathrm{Bi}(0)$. For the raw diffractogram, see Figure $\mathrm{S} 8$ in the Supporting Information.

X-ray Photoelectron Spectroscopy (XPS) analyses of Bi/P NPs provided further insight into their composition. The survey XPS spectrum of BiP.CD (Figure 3a) showed the presence of bismuth, phosphorus, oxygen, carbon and nitrogen, as expected. The HR-XPS spectrum in the region of $\mathrm{Bi} 4 \mathrm{f}$ (Figure $3 \mathrm{~b}$ ) indicated that two bismuth species are present; the more intense peaks with binding energies of 157.0 and $162.3 \mathrm{eV}$ correspond to $\mathrm{Bi}(0)$, in agreement with the data obtained by PXRD while the other two signals of minor intensity are attributed to $\mathrm{Bi}(\mathrm{III})$. Examination of the $\mathrm{P} 2 \mathrm{p}$ region (Figure 3c) revealed the existence of two peaks at 130.1 and $133.8 \mathrm{eV}$; the observed binding energy at $130.1 \mathrm{eV}$ is almost identical to that reported for red $\mathrm{P}$ $(130.0 \mathrm{eV}) ;{ }^{47}$ the broad signal at $133.8 \mathrm{eV}$ is probably due to the presence of phosphorus oxides (for deconvolution of signals, see Figure S9 in the Supporting Information). ${ }^{48,49}$ In fact, we repeatedly obtained this high energy signal despite performing the work-up of the resulting solid under $\mathrm{N}_{2}$ atmosphere, which indicates the high tendency of these NPs to be oxidized, also confirmed by NMR studies (see below). XPS data in the O 1s region (Figure 3d) revealed the presence of different kinds of species other than $\mathrm{CD}$; the large peak at $531 \mathrm{eV}$ probably arises from hydroxyl groups (the peak at $533 \mathrm{eV}$ is attributed to the wafer); a signal corresponding to Bi oxide species was identified as a shoulder at $530 \mathrm{eV} .{ }^{50}$ Peaks of low intensity detected in the I $3 \mathrm{~d}$ region ( $c a .619-631 \mathrm{eV}$ in Figure 3a) indicate the practically full consumption of $\mathrm{BiI}_{3}$. In the nitrogen region $(c a .400 \mathrm{eV})$, a weak signal was observed, proving the presence of the stabilizer $(\mathrm{CD})$. Thus, XPS analyses confirmed the presence of $\operatorname{Bi}(0)$ and $\mathrm{P}(0)$ together with some oxidized bismuth and phosphorus species, and cinchonidine. A similar information could be inferred from the XPS data corresponding to BiP.PVP, in this case observing clearly the signal corresponding to nitrogen (see Figure S9 in the Supporting Information). 


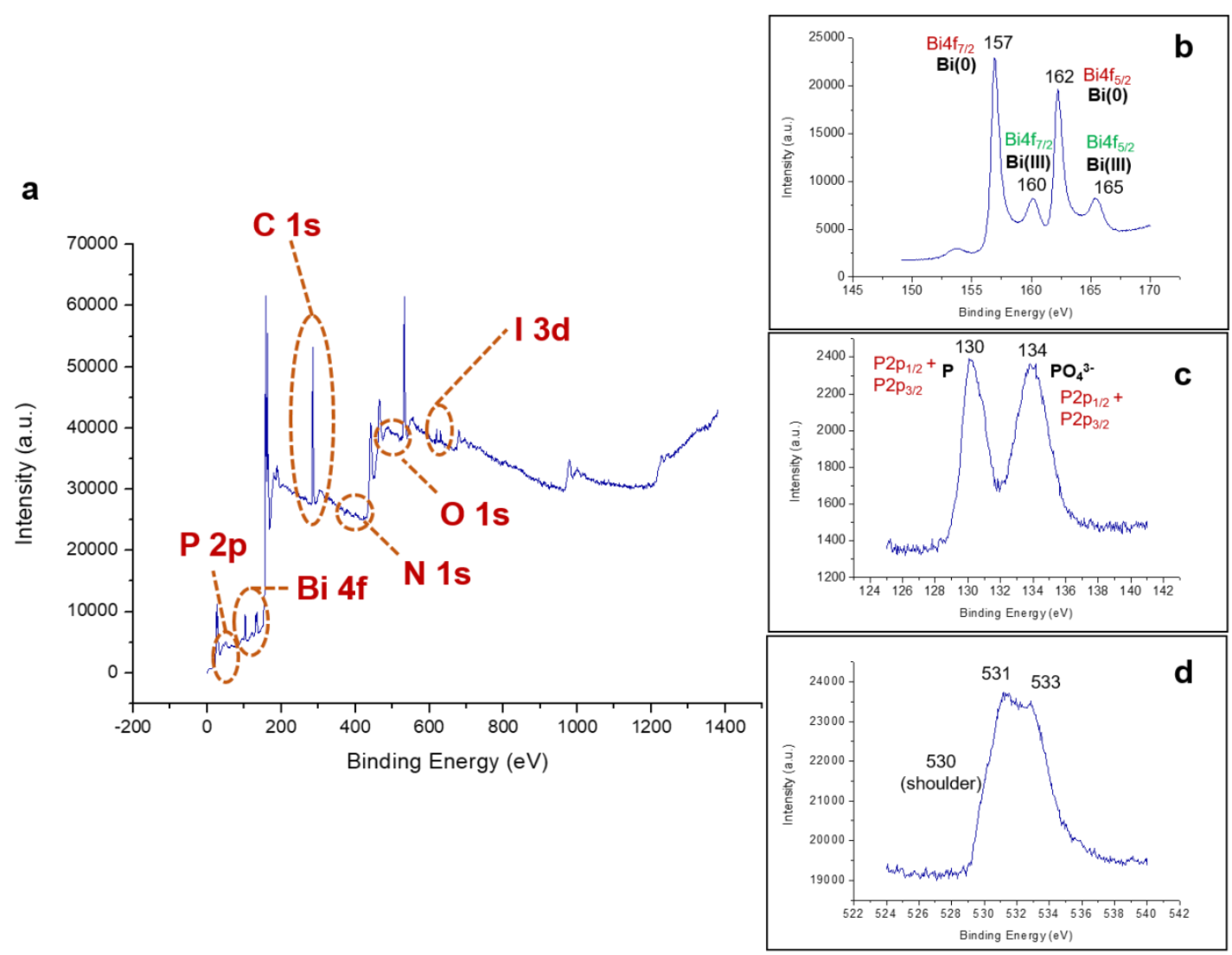

Figure 3. Survey XPS spectrum of BiP.CD (a) and its HR-XPS spectra in the regions of Bi (b), P (c) and $\mathrm{O}(\mathrm{d})$.

With the purpose of better understanding the structure of these Bi/P NPs, advanced ${ }^{1} \mathrm{H},{ }^{13} \mathrm{C}$ and ${ }^{31} \mathrm{P}$ solid state NMR experiments for BiP. CD were carried out. The rotor containing the sample was prepared inside a glovebox, in order to minimize the contact with air. The ${ }^{31} \mathrm{P}$ NMR spectrum was deconvoluted in four peaks (Figure 4). The broad signal at ca. $62 \mathrm{ppm}$ is attributed to amorphous $\mathrm{P}(0)$, in agreement with the reported data (chemical shift of $70 \mathrm{ppm}$ for red phosphorus, commonly observed as a broad singlet). ${ }^{51}$ The resonance at $-7 \mathrm{ppm}$ is assigned to phosphorus oxides. This latter signal was enhanced in the ${ }^{1} \mathrm{H}-{ }^{31} \mathrm{P}$ Cross-Polarization (CP) MAS NMR spectrum of the same sample (see Figure S10 in the Supporting Information), unambiguously showing that this resonance arose from P-based species located at the surface. ${ }^{52}$ Thus, these nanoparticles have to be considered as partially oxidized at their surface, despite the precautions taken during the synthesis and preparation of the sample for NMR analysis. Furthermore, a very broad signal centered at $c a .140 \mathrm{ppm}$ (signal A in Figure 5) was observed. 
This resonance was undoubtedly identified by recording a ${ }^{31} \mathrm{P}$ NMR spectrum with a very short relaxation delay of $2 \mathrm{~ms}$ (see Figure S11 in the Supporting Information). This broad signal with low frequency and short relaxation time is due to the Knight-shift effect triggered by metallic bismuth on the phosphorus atoms in close proximity to the metal surface. The resonance at this low frequency can be explained by the extra effective magnetic field induced by $\operatorname{Bi}(0)$ of the core. ${ }^{53}$ Moreover, a weak signal at $c a$. -104 ppm was also detected. The proximity of this chemical shift to that of some molecular species reported in the literature bearing Bi-P bonds, ${ }^{22,54}$ suggests the presence of an amorphous Bi-P phase in our system. It is noteworthy that the relative intensities of the signals observed in ${ }^{31} \mathrm{P}$ solid state NMR spectra are not directly related to their concentration. The presence of Bi probably diminishes the nuclear relaxation times of neighboring phosphorus atoms, due to relatively strong Fermi contact couplings. As a result of this efficient relaxation effect (known as Paramagnetic Relaxation Enhancement), the intensity of signals close to the paramagnetic centers can be significantly reduced or even imperceptible. $^{55}$

In brief, ${ }^{31} \mathrm{P}$ NMR spectroscopy provides a very important, although qualitative, picture of the Bi/P NPs synthesized, which feature several $\mathrm{P}$ environments: $\mathrm{P}$ in direct contact with metallic $\mathrm{Bi}$, amorphous $\mathrm{BiP}$, amorphous $\mathrm{P}(0)$ and oxidized $\mathrm{P}$ (most likely at the surface).

${ }^{13} \mathrm{C}$ MAS NMR spectra were recorded to probe the nature of surface ligands. As often observed for metal-based nanoparticles, the signals were very weak (see Figure S12 in the Supporting Information), which indicates that the organic part exhibits a limited motion. ${ }^{13} \mathrm{C} \mathrm{CP}$ MAS NMR spectrum showed three signals at 64.0, 28.4 (assigned to THF) and 0.0 ppm (most probably corresponding to silyl derivatives formed by reaction of TMSI with the hydroxyl groups on the surface, i.e. P-OH) (see Figure S12 in the Supporting Information). However, no signals corresponding to aromatic carbon atoms were observed, pointing to a negligible amount of ligand in the purified Bi/P NPs (below the detection limit of the NMR technique). When the

${ }^{13} \mathrm{C}$ CP MAS NMR spectrum of non-purified BiP.CD was recorded, the characteristic peaks of 
aromatic carbons at $c a .120 \mathrm{ppm}$ were certainly observed (see Figure S13 in the Supporting Information).

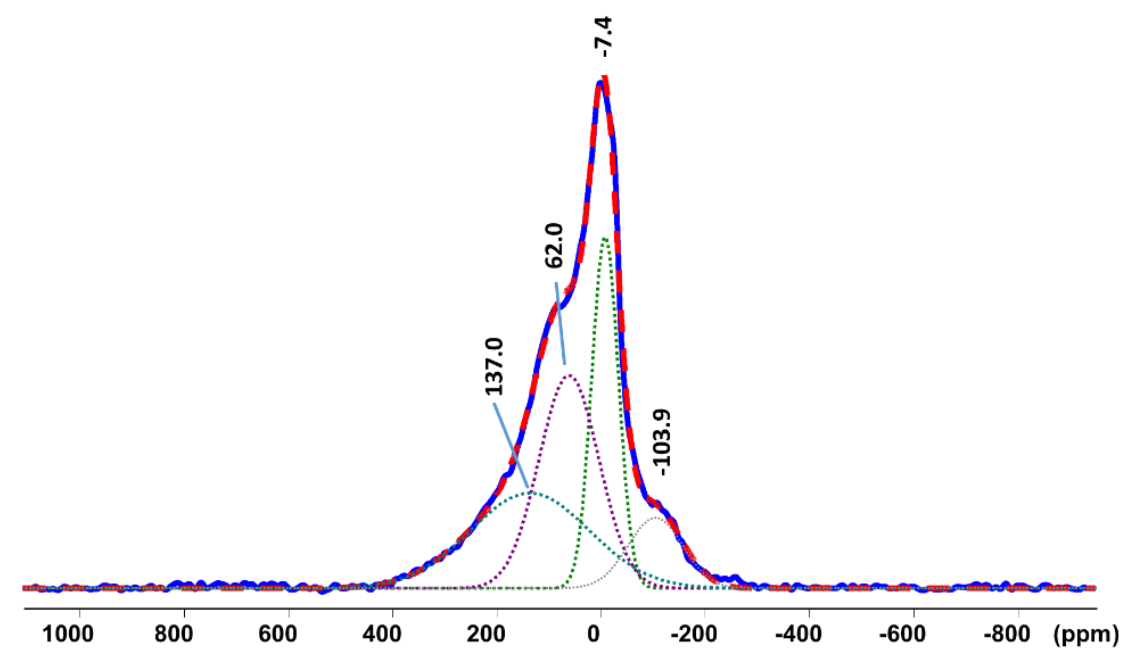

Figure 4. ${ }^{31} \mathrm{P}$ MAS NMR spectrum of BiP.CD including spectral deconvolution which reveals the presence of four peaks.

In the ${ }^{1} \mathrm{H}$ MAS NMR spectrum (see Figure S14 in the Supporting Information), a strong and sharp resonance appearing at $0 \mathrm{ppm}$ was attributed to the aforementioned silyl derivatives. The signal between 1 and 5 ppm was associated to THF. Broad resonances between 7 and 16 ppm can be assigned to hydroxyl groups involved in strong hydrogen bonds. The intensity of these last signals strongly increased with air exposition (vide infra) confirming the partial oxidation of the outermost P centers of the Bi/P NPs (see Figure S15 in the Supporting Information). This attribution was confirmed by ${ }^{1} \mathrm{H} /{ }^{31} \mathrm{P}$ FBCP experiment which provides a ${ }^{31} \mathrm{P}$-edited ${ }^{1} \mathrm{H}$ spectrum where only signals of hydrogen atoms in close proximity to the phosphorus ones are observed (see Figure S16 in the Supporting Information). Similar NMR experiments were also performed for BiP·PPP, obtaining a comparable behavior than that observed for BiP·CD (see Figures S17 and S18 in the Supporting Information).

In light of these results involving several characterization techniques, we can conclude that these materials do not consist on a BiP nano-alloy, but instead present a core-shell architecture based on a crystalline $\mathrm{Bi}(0)$ core surrounded by amorphous P-containing shells, including an 
inner $\mathrm{BiP}$ shell, and an amorphous $\mathrm{P}(0)$ outer shell partially oxidized at the surface, stabilized by different ligands. Most interestingly, this constitutes the first example of phase segregation between $\mathrm{M}$ and $\mathrm{P}$ in metal phosphides $\mathrm{M}_{\mathrm{x}} \mathrm{P}_{\mathrm{y}}$ nanoparticles. Note that $\mathrm{Cu}-\mathrm{Cu}_{3} \mathrm{P}$ Janus-like nanoparticles have been previously reported as a segregated structure; but, the $\mathrm{Cu}_{3} \mathrm{P}$ component of this nanostructure exhibits an alloy structure. ${ }^{56}$

However, the structural description provided at this point is limited, as the thickness of the shells was still unknown. To further characterize the structure of the as-prepared Bi/P-based nanomaterials, Small Angle X-ray Scattering experiments were performed (samples were prepared under the same conditions than those used to record solid state NMR). SAXS is a powerful technique to determine the morphology of nanoparticles or elucidate inter-particle arrangements in ordered systems. ${ }^{57}$ The X-ray scattering curves obtained for the three nanomaterials were very similar, both in glycerol dispersion and at solid state; however, in glycerol, SAXS analyses showed an important intensity decrease of the signals due to the loss of inter-particle correlation (present in solid state), associated to a better dispersion of nanoparticles in glycerol (see Figure S19 in the Supporting Information), in agreement with the TEM analyses (see above and Figure S20 in the Supporting Information). Only the case of BiP.CD in solid state is discussed here. At small and intermediate angles (0.01-0.1 $\left.\AA^{-1}\right)$, the linear increase of the intensity indicates the presence of aggregates whose surface can be described with a power law function. At medium and high angles $\left(0.1-1 \AA^{-1}\right)$, the SAXS curves were only fitted using a core-shell model function; attempts to fit them using other models for spherical nanoparticles (such as sphere model) did not provide an appropriate fit (Figure 5), thereby ruling out an alloy BiP phase. 


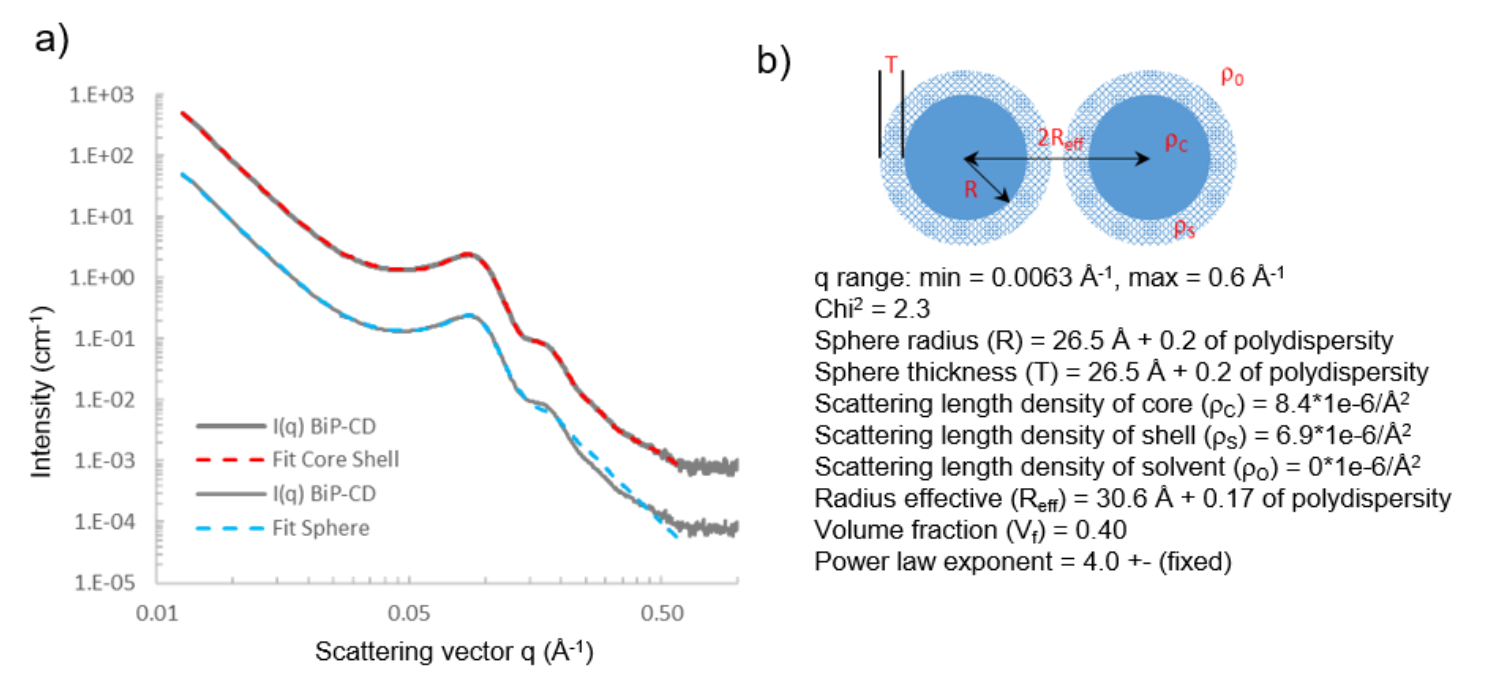

Figure 5. SAXS curves of BiP.CD in solid state (continuous grey line) and two models based on core shell spheres (red dashed line) or simple solid spheres (blue dashed line) with short distance interactions (a). SAXS parameters of the core shell model obtained after fitting performed with Sasview software (b).

The SAXS technique is sensitive to the contrast and can distinguish a core composed of Bi to a shell composed of $\mathrm{P}$. However, if the crystalline Bi core is surrounded by an intermediate shell containing Bi and P, SAXS will not be sensitive enough to discriminate this intermediate shell and will detect an apparent core. Thus, the experimental data point to a dense core constituted of crystalline $\operatorname{Bi}(0)$ and an amorphous shell of $\operatorname{BiP}\left(5.2 \pm 0.1 \mathrm{~nm}\right.$ diameter and 8.4.10 $0^{-6} \AA^{-2}$ scattering length density of core), surrounded by a lighter amorphous shell of $\mathrm{P}(0)$ completed by oxidized phosphorus moieties ( $c a .0 .85 \mathrm{~nm}$ thickness and $6.9 .10^{-6} \AA^{-2}$ scattering length density of shell). Similarly, TEM analyses provide contrast with the heavy Bi element, and thus likely to $\mathrm{Bi}$ (core) and BiP (shell). A comparison can thus be made between the size of the particles determined by TEM and SAXS data. Thus $2.3 \pm 0.7 \mathrm{~nm}$ measured on the images have to be compared with the $5.2 \pm 0.1 \mathrm{~nm}$ of "core" diameter calculated with SAXS, which is a reasonable match and the differences are probably due to the difference of sensibility of the two techniques. 
As mentioned above, despite performing the experiments under air free conditions, the $\mathrm{P}$ shell is partially oxidized at the surface. It was therefore of interest to probe the sensitivity of the core/shell/shell $\mathrm{Bi}$ (crystalline)/BiP(amorphous)/P(amorphous) material in the solid state with regard to oxygen. This reactivity was studied for BiP.CD at solid state both by ${ }^{31} \mathrm{P}$ NMR and SAXS analyses. ${ }^{31}$ P MAS NMR spectra were recorded at different times after exposition of the sample to air (Figure 6). It was observed that the relative intensity of the resonance $-7 \mathrm{ppm}$ increased (signal C in Figure 6), whereas the one at $62 \mathrm{ppm}$ significantly decreased (signal B in Figure 6), confirming the tendency of the amorphous $\mathrm{P}$ shell of the Bi/P NPs to be oxidized. In addition, both the broad signal centered at $c a .140 \mathrm{ppm}$ and the weak signal at $c a .-104 \mathrm{ppm}$ (signal A in Figure 6), also decreased in intensity with air exposition. This evolution of BiP.CD under air was also evidenced by the major changes in morphology and size observed by TEM. Nonetheless, PXRD proved the presence of crystalline Bi(0) (see Figure S21 in the Supporting Information).
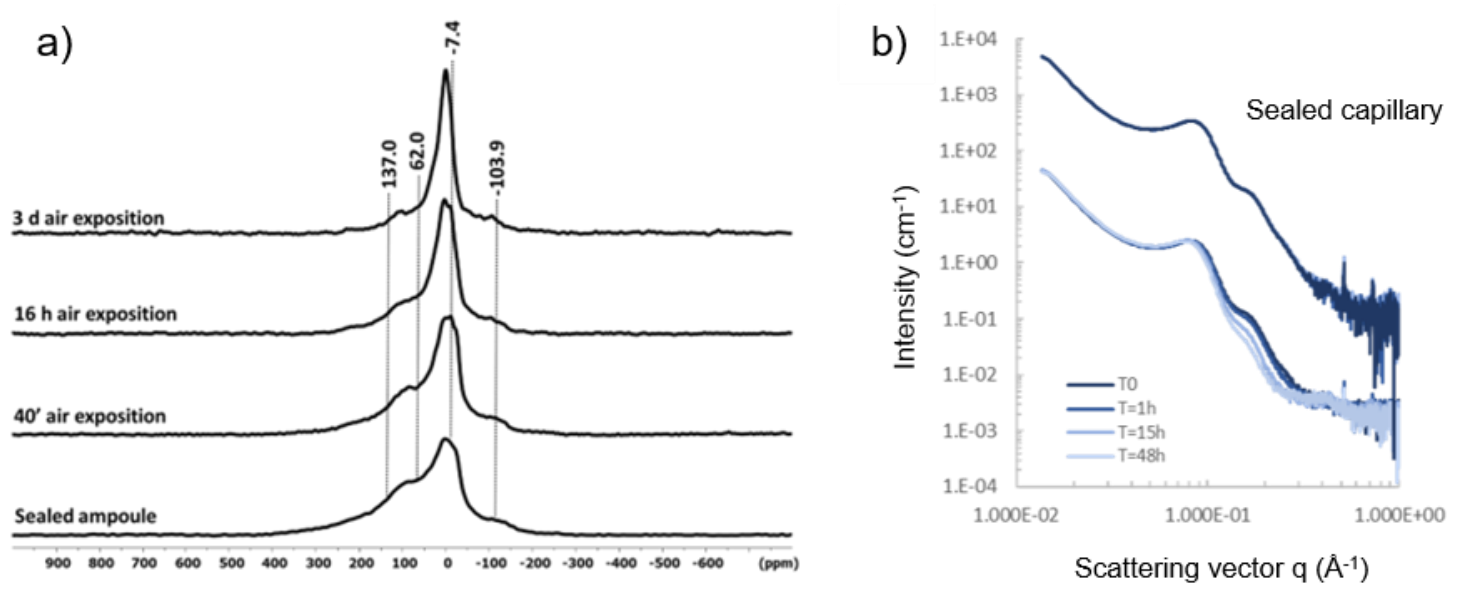

Figure 6. ${ }^{31}$ P MAS NMR spectrum (a) of BiP.CD as a function of time of air exposition (t0 sealed ampoule- and after 40 minutes, 16 hours and 3 days under air). SAXS curves (b) performed on BiP.CD in sealed capillary and on BiP.CD exposed to the air (t0 -sealed ampoule- and after 1 hour, 15 hours and 2 days under air)

The oxidation process of the as-prepared nanoparticles was also studied by SAXS. A series of ten SAXS analyses (between 30 minutes and $48 \mathrm{~h}$ ) were done exposing BiP.CD under air. A 
significant change in the curve could be observed linked to different intrinsic parameters of nanoparticles such as the core radius, the thickness of the shell, and the scattering length density. As evidenced by TEM after oxidation (see Figure S21 in the Supporting Information), particles of different sizes and shapes are formed, which hampers a satisfactory fitting of the curves.

Knowing accurately the core-shell structure of the Bi/P NPs, we were interested in their reactivity and several questions arose. Firstly, does the oxidized surface of the shell provide an efficient passivation, thereby preventing reactivity? Secondly, if not, will the $\mathrm{P}(0)$ in the shell possess a reactivity different than red (amorphous) and white allotropes of phosphorus? This would be an interesting feature as red phosphorus is easier to handle and not as toxic as white phosphorus, but it is conversely far less reactive than the white allotrope. We have shown in the past that red $\mathrm{P}$ reacts quantitatively with $\mathrm{Br}_{2}$ to form $\mathrm{PBr}_{3}$ and in the presence of an excess of $\mathrm{Br}_{2}$ to form $\mathrm{PBr}_{5}{ }^{58}$ In order to verify the accessibility of the phosphorus shell in our $\mathrm{Bi} / \mathrm{P}$ NPs despite the existence of phosphorus oxides, the reactivity of the three types of nanoparticles towards $\mathrm{Br}_{2}$ was evaluated at room temperature (Scheme 2).

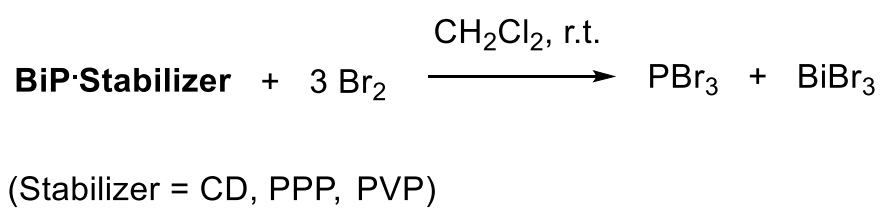

Scheme 2. Reactivity of Bi/P NPs with regard to bromine (for stabilizers, see Scheme 1).

A total of three equivalents of $\mathrm{Br}_{2}$ are needed to oxidize in a stoichiometric fashion both $\mathrm{Bi}(0)$ and $\mathrm{P}(0)$ to the corresponding bromide derivatives, $\mathrm{BiBr}_{3}$ and $\mathrm{PBr}_{3}$. Bromine was added portion wise and ${ }^{31} \mathrm{P}$ NMR spectra recorded after each addition (Figure 7 for BiP.CD; see Figure S22 in the Supporting Information for BiP.PVP). $\mathrm{PBr}_{3}$ (singlet at $229 \mathrm{ppm}$ in the ${ }^{31} \mathrm{P}$ NMR spectrum) was the only species formed up to $25 \%$ of the total amount of $\mathrm{Br}_{2}$ added; after $50 \% \mathrm{of}^{\mathrm{Br}_{2}}$ addition, a new signal appears at $-101 \mathrm{ppm}$, consistent with the formation of minor amounts of $\mathrm{PBr}_{5}$. After addition of 1 equiv. of $\mathrm{Br}_{2}$, we obtained both products in an approximatively ratio 
$\mathrm{PBr}_{3} / \mathrm{PBr}_{5}$ of $4 / 1$. In addition to these soluble P-based species, a yellow solid was formed. This solid was separated, washed, dried and analyzed by ICP. Its composition correlated with $\left(\mathrm{BiBr}_{3}\right)_{0.7}\left(\mathrm{PBr}_{5}\right)_{0.3}$, thus confirming the presence of $\mathrm{PBr}_{5}$ in the solid (see Figure $\mathrm{S} 23$ in the Supporting Information). The formation of such over-oxidation product of $\mathrm{PBr}_{3}$ is due to the excess of $\mathrm{Br}_{2}$ added.

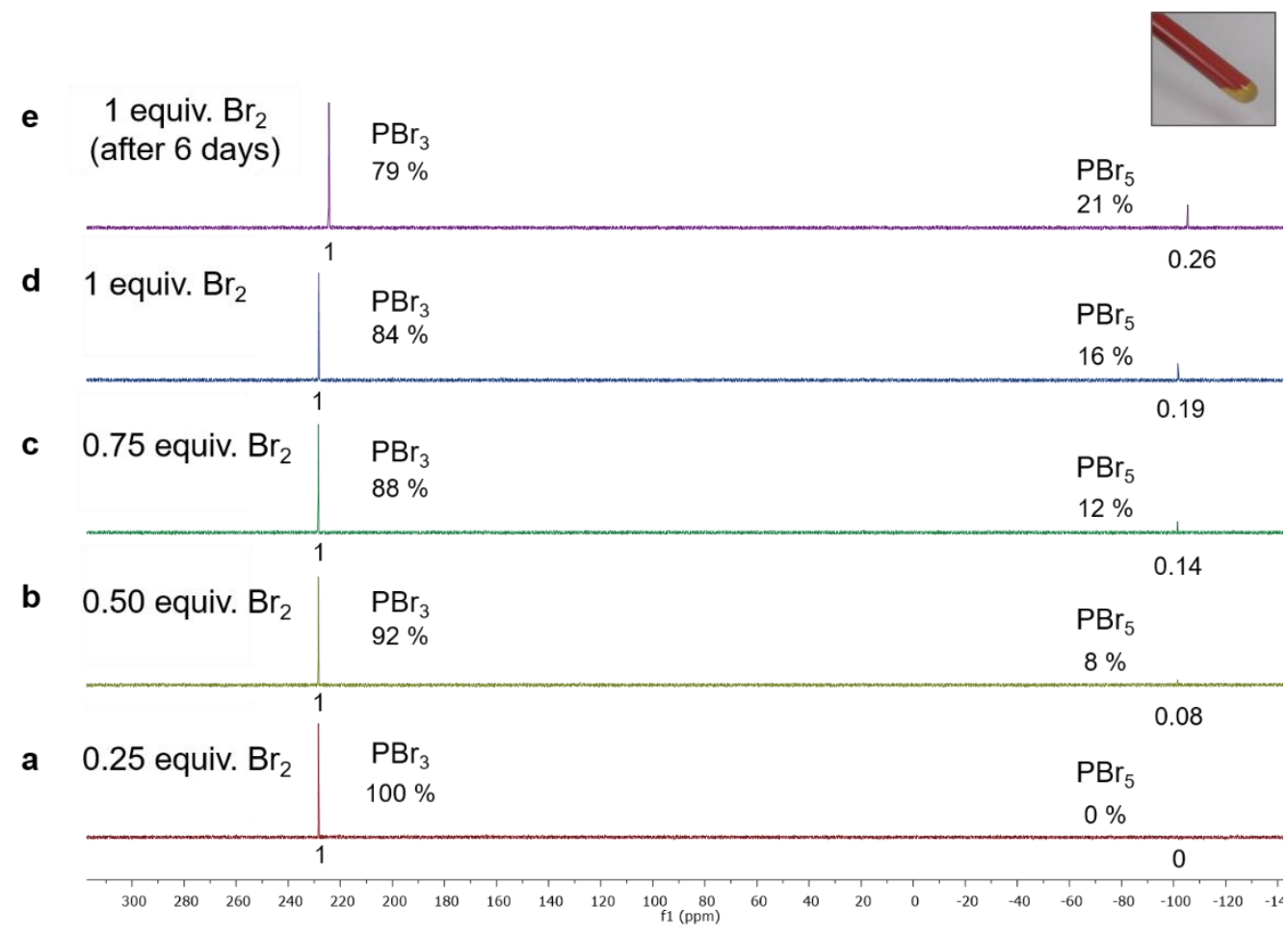

Figure 7. ${ }^{31} \mathrm{P}\left\{{ }^{1} \mathrm{H}\right\}$-NMR spectra (121.5 MHz) of a dispersion of $\mathbf{B i P} \cdot \mathbf{C D}$ in $\mathrm{CH}_{2} \mathrm{Cl}_{2}$ after the addition of: a) 0.25 equiv., b) 0.5 equiv., c) 0.75 equiv., d) 1 equiv., e) 1 equiv. (after 6 days) of bromine at room temperature.

Actually, this experiment supported that the $\mathrm{P}$ atoms are available in the core-shell $\mathrm{Bi} / \mathrm{P} \mathrm{NPs}$, mainly as elemental $\mathrm{P}(0)$. Although solid state NMR showed the presence of phosphorus oxides (probably formed during the analyses), oxide species were not observed upon reaction with $\mathrm{Br}_{2}$ which led to the formation of soluble species. This confirms that the solid state ${ }^{31} \mathrm{P}$ NMR analyses provide qualitative rather than quantitative information on the nature of the $\mathrm{P}$ species in the Bi/P NPs. With this positive result, we then pursued to a more challenging use of $\mathrm{P}(0)$ contained in our $\mathrm{Bi} / \mathrm{P} \mathrm{NPs}$, namely the synthesis of $\mathrm{PH}_{3} . \mathrm{PH}_{3}$ is industrially synthesized from 
white phosphorus through hydrothermal processes which typically require high temperature $\left(180{ }^{\circ} \mathrm{C}\right)$, long reaction times $(15 \mathrm{~h})$ and basic $\mathrm{pH} .{ }^{24,59}$ It involves a redox process that generates $\mathrm{KH}_{2} \mathrm{PO}_{2}$ as the oxidized $\mathrm{P}$ species concomitant with the reduced $\mathrm{PH}_{3}$ species. It is interesting to note that the ratio between $\mathrm{PH}_{3}$ and $\mathrm{KH}_{2} \mathrm{PO}_{2}$ depends on the kinetics of the reaction between $\mathrm{P}_{4}$ and the base, with a large preference for the formation of $\mathrm{KH}_{2} \mathrm{PO}_{2}{ }^{59}$ On the other hand, red $\mathrm{P}$ does not react under these conditions to form $\mathrm{PH}_{3}$. In our case, Bi/P NPs were treated with a stoichiometric amount of $\mathrm{KOH}$ in the presence of water (Scheme 3), and the reaction monitored by ${ }^{31} \mathrm{P}$ NMR (Figure 8 ).

$$
\begin{aligned}
& \text { BiP.Stabilizer }+3 \mathrm{KOH}+3 \mathrm{H}_{2} \mathrm{O} \frac{\mathrm{THF}}{80^{\circ} \mathrm{C}, 3 \mathrm{~h}} 3 \mathrm{KH}_{2} \mathrm{PO}_{2}+\mathrm{PH}_{3}+\mathrm{BiO}_{\mathrm{x}} \\
& \text { (Stabilizer }=\mathrm{CD} \text {, PPP, PVP) }
\end{aligned}
$$

Scheme 3. Reactivity of Bi/P NPs with KOH (for stabilizers, see Scheme 1).

Most pleasingly, $\mathrm{PH}_{3}$ was formed as the major species (quadruplet at $-245 \mathrm{ppm}$ ) together with $\mathrm{KH}_{2} \mathrm{PO}_{2}$ (broad doublet at $c a .5 .4 \mathrm{ppm},{ }^{1} J_{\mathrm{P}-\mathrm{H}} c a 480 \mathrm{~Hz}$ ) from BiP. CD in a saturated aqueous solution of $\mathrm{KOH}$ under smooth conditions $\left(80^{\circ} \mathrm{C}, 3 \mathrm{~h}\right.$ ) (for BiP·PVP and BiP·PPP, see Figures S24-S25 in the Supporting Information).

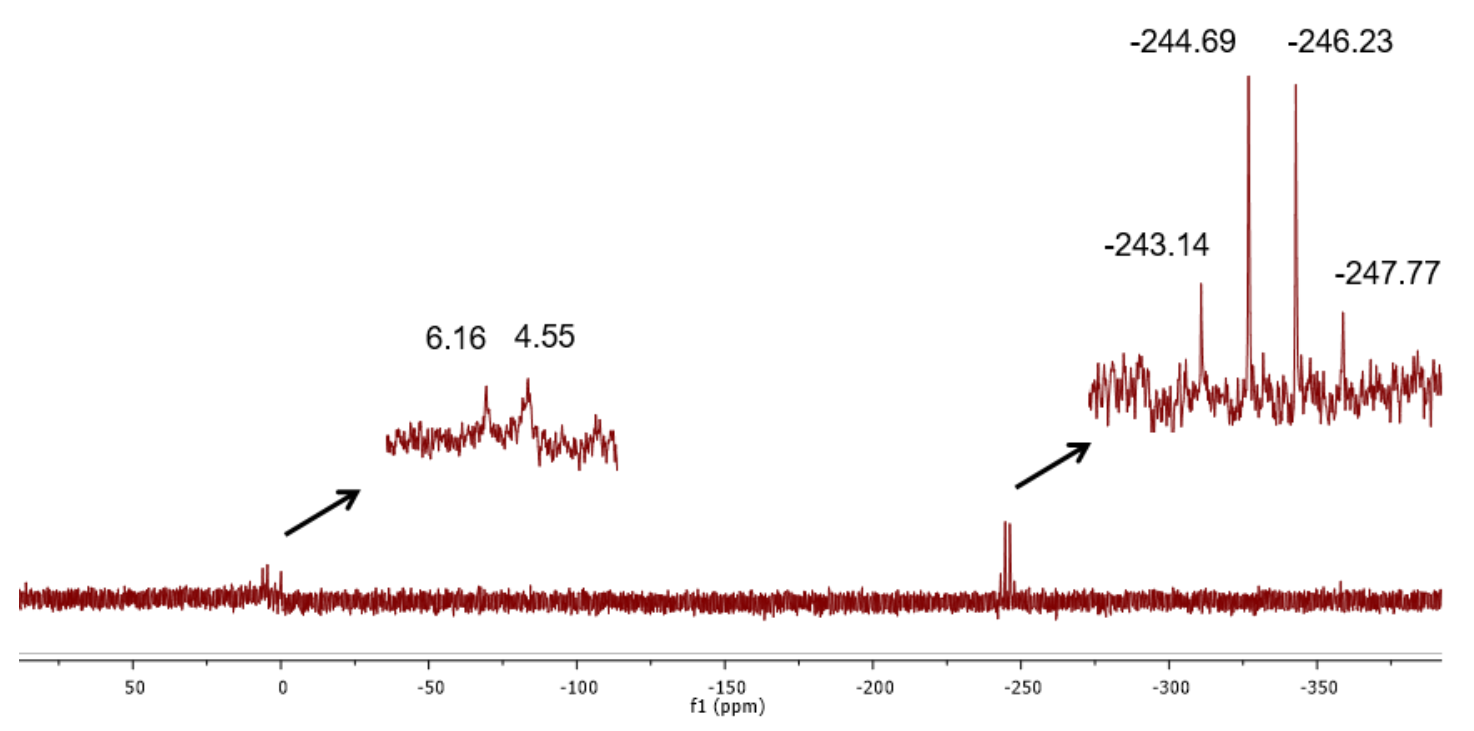


Figure 8. ${ }^{31} \mathrm{P}-\mathrm{NMR}$ spectrum (121.5 MHz) in THF showing the formation of $\mathrm{PH}_{3}(-245 \mathrm{ppm})$ by reaction of $\mathbf{B i P} \cdot \mathbf{C D}$ with $\mathrm{KOH}(\mathrm{aq}$.$) together with \mathrm{KH}_{2} \mathrm{PO}_{2}$ (ca. $\left.5.4 \mathrm{ppm}\right)$.

It has been reported in the literature that the crucial reason for the low temperature reactivity of $\mathrm{P}_{4}$ compared to other allotropes is its constrained tetrahedral geometry. ${ }^{24} \mathrm{We}$ thus believe that the high surface-to-volume ratio of the Bi/P NPs together with their solubility in common organic solvents, renders elemental $\mathrm{P}(0)$ found in the shell of the particles more reactive, explaining their reactivity towards $\mathrm{KOH}$, comparable to $\mathrm{P}_{4}$.

Thus, the original core-shell structure of $\mathrm{Bi} / \mathrm{P}$ NPs provides a new reactive form of phosphorus that can be used as a safer alternative compared with white phosphorus, $\mathrm{P}_{4}$.

\section{CONCLUSIONS}

This work reports the synthesis of $\mathrm{Bi} / \mathrm{P}$ nanomaterials together with a comprehensive analysis of their composition and structure. To the best of our knowledge, this is the first time in which nanoparticles of binary phosphides of group 15 elements are unequivocally described. TEM analyses evidenced the formation of small NPs with good size dispersion. Powder XRD studies ruled out the possibility of the existence of a crystalline BiP phase, while XPS pointed to the existence of $\mathrm{Bi}(0)$ and $\mathrm{P}(0)$ together with minor amounts of oxidized $\mathrm{Bi}$ and $\mathrm{P} .{ }^{31} \mathrm{P}$ MAS NMR experiments further refined the understanding of the nature of "BiP" NPs, showing the presence of amorphous $\mathrm{P}(0), \mathrm{P}$ in proximity to metallic $\mathrm{Bi}$, a minor $\mathrm{BiP}$ structure and phosphorus oxides. Moreover, SAXS analyses proved that these NPs display a more complex structure involving a crystalline $\mathrm{Bi}(0)$-core and amorphous P-containing shells. This type of structure represents the first example of phase segregation for metal phosphides at the nanoscale. Kinetic studies concerning this phenomenon in the $\mathrm{Bi} / \mathrm{P}$ nanoparticles are underway.

The monitoring (ssNMR, SAXS) of the aerobic oxidation of the core/shell nanoparticles revealed the evolution of the phosphorus containing shells (amorphous BiP and $\mathrm{P}(0)$ ) leading to oxidized phosphorus triggering major changes in morphology (TEM). 
This study also provides evidences of the unexpected reactivity of the phosphorus phase, exhibiting properties of both white $\mathrm{P}_{4}$ and red $\mathrm{P}$ allotropes. This is of remarkable importance since it provides a safer alternative than $\mathrm{P}_{4}$ and paves the way for further developments as source of phosphorus atom donor.

\section{EXPERIMENTAL SECTION}

General. All reactions and manipulations were carried out in a glovebox under $\mathrm{N}_{2}$ atmosphere, or using standard Schlenk techniques under Ar atmosphere. Dry, oxygen-free solvents were employed. They were distilled from a MB SPS-800 solvent purification system and degassed. All starting materials were used as received without further purification except for NaI, which was dried under dynamic vacuum prior to use. TEM micrographs of particles dispersed in glycerol and dichloromethane were obtained from a JEOL JEM 1400 microscope running at $120 \mathrm{kV}$, at the "Centre de Micro Caractérisation Raimond Castaing". The size, distribution and average diameter of nanoparticles were determined from TEM images with Image-J software associated to a Microsoft Excel macro developed by Christian Pradel. DRX analyses were run by the Technical platform of the ICT ("Institut de Chimie de Toulouse", FR2599). The powder X-ray diffraction patterns were collected by using a XPert Pro (ThetaTheta mode) Panalytical diffractometer with $\alpha(\mathrm{Cu} \mathrm{K} \alpha 1, \mathrm{~K} \alpha 2)=1.54060$ and $1.54443 \AA$. ICPAES analyses were carried out at the "Service d'Analyse" of Laboratoire de Chimie de Coordination (Toulouse) using an iCAP 6300 ICP spectrometer. X-ray photoelectron spectroscopy (XPS) studies were run at the "Institut Català de Nanociència i Nanotecnologia (ICN2, Barcelona)" and performed on a SPECS Phoibos 150 hemispherical energy analyzer with a non-monochromatic Al Ka X-ray source (1486.6 eV and $300 \mathrm{~W}$ ) placed perpendicularly to the analyzer axis and calibrated using the $1 \mathrm{~s}$ line of $\mathrm{C}$. The measurements were made in ultrahigh vacuum at residual pressure around $10^{-8} \mathrm{~Pa}$. Solution ${ }^{31} \mathrm{P}-\mathrm{NMR}$ experiments were carried out at the Technical platform of the ICT. NMR spectra were recorded on a Bruker Advance 300 spectrometer at $293 \mathrm{~K}$. Chemical shifts $(\delta)$ are expressed in parts per million and are referenced internally to $85 \% \mathrm{H}_{3} \mathrm{PO}_{4}$. Solid state NMR experiments were recorded on Bruker Advance 400 
III HD spectrometers operating at magnetic fields of $9.4 \mathrm{~T}$. Samples were packed into $2.5 \mathrm{~mm}$ zirconia rotors inside a glove box under a dinitrogen atmosphere. The rotors were spun at 18 $\mathrm{kHz}$ at $293 \mathrm{~K} .{ }^{1} \mathrm{H}$ MAS were performed with DEPTH pulse sequence and a relaxation delay of 3 s. ${ }^{31} \mathrm{P}$ Hahn-echo were acquired with recycle delays between $30 \mathrm{~s}$ and $20 \mathrm{~ms}$. For ${ }^{13} \mathrm{C}$ single pulse MAS experiments, a recycle delay of $3 \mathrm{~s}$ was used. ${ }^{13} \mathrm{C} \mathrm{CP}$ and ${ }^{31} \mathrm{P} C \mathrm{CP}$ MAS spectra were recorded with a recycle delay of $1.5 \mathrm{~s}$, and contact times of $2 \mathrm{~ms}$ and $1 \mathrm{~ms}$, respectively. The ${ }^{1} \mathrm{H}-$ ${ }^{31} \mathrm{P}$ FBCP NMR method was performed with a first $\mathrm{CP}$ transfer of $3 \mathrm{~ms}$ and a second $\mathrm{CP}$ contact of $2 \mathrm{~ms}^{60}$ Chemical shifts for ${ }^{1} \mathrm{H}$ and ${ }^{13} \mathrm{C}$ are relative to TMS. ${ }^{31} \mathrm{P}$ chemical shifts were referenced to an external $85 \% \mathrm{H}_{3} \mathrm{PO}_{4}$ sample. SAXS measurements were performed on the XEUSS 2.0 laboratory source equipped with a pixel detector PILATUS 1M (DECTRIS) and an X-ray source provided by a GeniX3D with a fixed wavelength based on $\mathrm{Cu} \mathrm{K} \alpha$ radiation $(\lambda=1.54 \AA)$. The sample to detector distance was fixed at $567.5 \mathrm{~mm}$ giving a $q$ range starting from $0.12 \AA^{-1}$ to $1 \AA^{-1}$ assuming that $q$ is the scattering vector equal to $4 \pi / \lambda \sin \theta$ with $2 \theta$ the scattering angle. The distance was calibrated in the small angle's region using silver behenate $\left(\mathrm{d}_{001}=58.34 \AA\right)$. At the beginning, the powders of $\mathrm{Bi} / \mathrm{P}$ nanoparticles were stored on sealed capillaries to prevent oxidation and placed on motorized sample holder. To remove scattering and absorption from air, a primary vacuum has been applied to the entire instrument. For the kinetic experiences, the top of the capillary was broken to restore oxygen diffusion. Acquisition time per sample was 30 minutes and all scattering curves were corrected for the empty capillary contribution, divided by transmission factor, acquisition time and optical path in order to obtain SAXS curves in absolute units $\left(\mathrm{cm}^{-1}\right)$.

Synthesis of BiP.CD. In the glovebox, a solution of $\mathrm{P}\left(\mathrm{SiMe}_{3}\right)_{3}(0.24 \mathrm{~mL}, 0.8 \mathrm{mmol})$ in 0.5 $\mathrm{mL}$ of THF was quickly injected into a vigorously stirred solution of $\mathrm{BiI}_{3}(0.24 \mathrm{~g}, 0.4 \mathrm{mmol})$, $\mathrm{NaI}(0.06 \mathrm{~g}, 0.4 \mathrm{mmol})$ and cinchonidine $(0.02 \mathrm{~g}, 0.07 \mathrm{mmol})$ in $12 \mathrm{~mL}$ of THF. The solution color changed rapidly from brown to black, this feature indicating the formation of NPs. The reaction mixture was left overnight under stirring at room temperature; the colorless supernatant of the reaction mixture was analyzed by ${ }^{31} \mathrm{P}$ NMR proving the presence of unreacted $\mathrm{P}(\mathrm{TMS})_{3}$ 
(see Figure S26 in the Supporting Information). Bi/P NPs in the solid state were isolated from THF solutions by centrifugation at 6000 r.p.m. for 20 minutes and washed with THF $(2 \times 24$ $\mathrm{mL}$ ) to get rid of salts and excess of $\mathrm{P}\left(\mathrm{SiMe}_{3}\right)_{3}$, pumped to dryness in the vacuum line and kept in the glovebox under dinitrogen atmosphere until further characterization $(0.075 \mathrm{~g})$. ICP analyses gave the following percentage composition (calculated values in parentheses): $\mathrm{Bi}, 83.8$ (87.1); $\mathrm{P}, 11.6$ (12.9), corresponding to a molar ratio $\mathrm{Bi}: \mathrm{P}=1: 1.3$. Not taking into account the CD stabilizer, a yield of $75 \%$ (based on $\mathrm{BiI}_{3}$ ) was calculated.

Synthesis of BiP.PVP of and BiP.PPP were prepared following the same procedure than that for BiP.CD, replacing CD by PVP (average molecular weight 10,000 g/mol) and PPP (0.078 g of PVP and $0.079 \mathrm{~g}$ of PPP). Not taking into account the stabilizer, yields of $73 \%$ and $83 \%$ (based on $\mathrm{BiI}_{3}$ ) are calculated assuming BiP stoichiometry for BiP.PVP and BiP.PPP respectively.

Reactivity towards $\mathbf{B r}_{2}$. The stoichiometric quantity of $\mathrm{Br}_{2}\left(13 \mu \mathrm{L}, 2.5 \cdot 10^{-4} \mathrm{~mol}\right.$ of $\left.\mathrm{Br}_{2}\right)$ was progressively added to preformed Bi/P NPs $\left(20 \mathrm{mg}, 8.3 \cdot 10^{-5} \mathrm{~mol}\right.$ of $\left.\mathrm{Bi} / \mathrm{P}\right)$ dispersed in $0.8 \mathrm{~mL}$ of THF, under argon. A ${ }^{31} \mathrm{P}-\mathrm{NMR}$ spectrum was recorded after each addition of $\mathrm{Br}_{2}(0.25$ equiv. on the stoichiometric amount).

Reactivity towards KOH. An aqueous solution of $\mathrm{KOH}\left(16.5 \mathrm{mg}, 2.5 \cdot 10^{-4} \mathrm{~mol}\right.$ of $\left.\mathrm{KOH}\right)$ was added to an NMR tube containing preformed Bi/P NPs (20 mg, 8.3.10 $0^{-5} \mathrm{~mol}$ of Bi/P) dispersed in $0.8 \mathrm{~mL}$ of THF. The reaction mixture was heated at $80{ }^{\circ} \mathrm{C}$ for $1 \mathrm{~h}$ and analyzed by ${ }^{31}$ P-NMR.

\section{Supporting Information}

The Supporting Information is available free of charge on the ACS Publications website. It contains additional TEM images, XPS, X-ray fluorescence, powder XRD data, solid state NMR spectra and SAXS data analysis. 


\section{AUTHOR INFORMATION}

\section{Corresponding Authors}

*E-mails: mezailles@,chimie.ups-tlse.fr, gomez@chimie.ups-tlse.fr

\section{ORCID}

Nicolas Mézailles: 0000-0001-8735-6285

Montserrat Gómez: 0000-0003-1211-1333

\section{Notes}

The authors declare no competing financial interest.

\section{ACKNOWLEDGMENTS}

Financial support from the DGA-Rapid program, the Centre National de la Recherche Scientifique (CNRS) and the Université Toulouse 3 - Paul Sabatier are gratefully acknowledged. Authors thank Sonia Mallet-Ladeira, Christian Pradel and Guillaume Sauthier for their fruitful discussions about PXRD, TEM and XPS analyses respectively. P. R. thanks the CNRS, the Université of Toulouse and the FERMaT Federation FR3089 for providing Small Angle X-Ray Scattering laboratory facility.

\section{REFERENCES}

(1) Cheng, X.; Pan, Z.; Lei, C.; Jin, Y.; Yang, B.; Li, Z.; Zhang, X.; Lei, L.; Yuan, C.; Hou, Y. A Strongly Coupled 3D Ternary Fe2O3@Ni2P/Ni(PO3)2 Hybrid for Enhanced Electrocatalytic Oxygen Evolution at Ultra-High Current Densities. $J$. Mater. Chem. A 2019, 7, 965-971. https://doi.org/10.1039/C8TA11223A. 
(2) Dai, X.; Zhang, L.; Jiang, Y.; Li, H. Tuning Electronic Properties of Boron Phosphide Nanoribbons by Edge Passivation and Deformation. Phys. Chem. Chem. Phys. 2019, 21, 15392-15399. https://doi.org/10.1039/C9CP02602A.

(3) Gong, N.; Deng, C.; Wu, L.; Wan, B.; Wang, Z.; Li, Z.; Gou, H.; Gao, F. Structural Diversity and Electronic Properties of 3d Transition Metal Tetraphosphides, TMP4 (TM = V, Cr, Mn, and Fe). Inorg. Chem. 2018, 57, 9385-9392. https://doi.org/10.1021/acs.inorgchem.8b01380.

(4) Gupta, S. K. D. B. S. K. Two-Dimensional Silicon Phosphide: Low Effective Mass and Direct Band Gap for Future Devices Applications. J. Mater. Sci. 2019, $54,11878-11888$.

(5) Kim, B.; Toprasertpong, K.; Paszuk, A.; Supplie, O.; Nakano, Y.; Hannappel, T.; Sugiyama, M. GaAsP/Si Tandem Solar Cells: Realistic Prediction of Efficiency Gain by Applying Strain-Balanced Multiple Quantum Wells. Sol. Energy Mater. Sol. Cells 2018, 180, 303-310. https://doi.org/https://doi.org/10.1016/j.solmat.2017.06.060.

(6) Kumar, A.; Thakur, P. R.; Sharma, G.; Naushad, M.; Rana, A.; Mola, G. T.; Stadler, F. J. Carbon Nitride, Metal Nitrides, Phosphides, Chalcogenides, Perovskites and Carbides Nanophotocatalysts for Environmental Applications. Environ. Chem. Lett. 2019, 17, 655-682. https://doi.org/10.1007/s10311-0180814-8 LB - Kumar2019.

(7) Liu, K.; Zhang, C.; Sun, Y.; Zhang, G.; Shen, X.; Zou, F.; Zhang, H.; Wu, Z.; Wegener, E. C.; Taubert, C. J.; et al. High-Performance Transition Metal Phosphide Alloy Catalyst for Oxygen Evolution Reaction. ACS Nano 2018, 12, 
158-167. https://doi.org/10.1021/acsnano.7b04646.

(8) Miao, J.-H. Y. Z.-Q. S.-F. W.-H. X. authorXiang-S. Planar Penta-Transition Metal Phosphide and Arsenide as Narrow-Gap Semiconductors with Ultrahigh Carrier Mobility. J. Mater. Sci. 2019, 54, 7035-7047.

(9) Yuan, J.-H.; Zhang, B.; Song, Y.-Q.; Wang, J.-F.; Xue, K.-H.; Miao, X.-S. Planar Penta-Transition Metal Phosphide and Arsenide as Narrow-Gap Semiconductors with Ultrahigh Carrier Mobility. J. Mater. Sci. 2019, 54, 7035-7047. https://doi.org/10.1007/s10853-019-03380-4 LB - Yuan2019.

(10) Greenwood, N. N.; Earnshaw, A. Chemistry of the Elements; Pergamon: Oxford, 1984.

(11) Ekwo, P. I.; Okeke, C. E. Thermoelectric Properties of the PbS $\square$ ZnS Alloy Semiconductor and Its Application to Solar Energy Conversion. Energy Convers. Manag. 1992, 33, 159-164. https://doi.org/https://doi.org/10.1016/01968904(92)90121-C.

(12) Hu, L.; Huang, S.; Patterson, R.; Halpert, J. E. Enhanced Mobility in PbS Quantum Dot Films via PbSe Quantum Dot Mixing for Optoelectronic Applications. J. Mater. Chem. C 2019, 7, 4497-4502. https://doi.org/10.1039/C8TC06495D.

(13) Humphrey, J. N. Optimum Utilization of Lead Sulfide Infrared Detectors under Diverse Operating Conditions. Appl. Opt. 1965, 4, 665-675. https://doi.org/10.1364/AO.4.000665.

(14) Ishida, A.; Muramatsu, K.; Ishino, K.; Fujiyasu, H. Laser Application of Pb1- 
XSrxS Films Prepared by Hot Wall Epitaxy. Semicond. Sci. Technol. 1990, 5, S334-S337. https://doi.org/10.1088/0268-1242/5/3s/075.

(15) Miskin, C. K.; Deshmukh, S. D.; Vasiraju, V.; Bock, K.; Mittal, G.; DuboisCamacho, A.; Vaddiraju, S.; Agrawal, R. Lead Chalcogenide Nanoparticles and Their Size-Controlled Self-Assemblies for Thermoelectric and Photovoltaic Applications. ACS Appl. Nano Mater. 2019, 2, 1242-1252. https://doi.org/10.1021/acsanm.8b02125.

(16) Mughal, F.; Muhyuddin, M.; Rashid, M.; Ahmed, T.; Akram, M. A.; Basit, M. A. Multiple Energy Applications of Quantum-Dot Sensitized TiO2/PbS/CdS and TiO2/CdS/PbS Hierarchical Nanocomposites Synthesized via p-SILAR Technique. Chem. Phys. Lett. 2019, 717, 69-76. https://doi.org/https://doi.org/10.1016/j.cplett.2019.01.010.

(17) You, C.; Zhang, G.; Deng, W.; Zhao, C.; An, B.; Liu, B.; Wang, B.; Yan, H.; Liu, D.; Zhang, Y. Cascade-Type Energy Band Design of a Black Phosphorus Photodetector with High Performance. J. Mater. Chem. C 2019, 7, 2232-2239. https://doi.org/10.1039/C8TC05735D.

(18) Brown, A.; Rundqvist, S. Refinement of the Crystal Structure of Black Phosphorus. Acta Crystallogr. 1965, 19 (4), 684-685. https://doi.org/10.1107/S0365110X65004140.

(19) Mellor, J. W. Comprehensive Treatise on Inorganic and Theoretical Chemistry; Green \& Co. Ltd.: London, 1928.

(20) Carmalt, C. J.; Cowley, A. H.; Hector, A. L.; Norman, N. C.; Parkin, I. P. A Synthesis of Bismuth(III) Phosphide: The First Binary Phosphide of Bismuth. J. 
Chem. Soc. Chem. Commun. 1994, 1987-1988.

https://doi.org/10.1039/C39940001987.

(21) Allen, G. C.; Carmalt, C. J.; Cowley, A. H.; Hector, A. L.; Kamepalli, S.; Lawson, Y. G.; Norman, N. C.; Parkin, I. P.; Pickard, L. K. Preparation and Characterization of a Material of Composition BiP (Bismuth Phosphide) and Other Intergroup 15 Element Phases. Chem. Mater. 1997, 9, 1385-1392. https://doi.org/10.1021/cm960606f.

(22) Schwamm, R. J.; Lein, M.; Coles, M. P.; Fitchett, C. M. Bi-P Bond Homolysis as a Route to Reduced Bismuth Compounds and Reversible Activation of P4. Angew. Chemie Int. Ed. 2016, 55 (47), 14798-14801. https://doi.org/10.1002/anie.201608615.

(23) Carenco, S.; Resa, I.; Le Goff, X.; Le Floch, P.; Mézailles, N. White Phosphorus as Single Source of "P" in the Synthesis of Nickel Phosphide. Chem. Commun. 2008, No. 22, 2568-2570. https://doi.org/10.1039/B802454E.

(24) Carenco, S.; Demange, M.; Shi, J.; Boissière, C.; Sanchez, C.; Le Floch, P.; Mézailles, N. White Phosphorus and Metal Nanoparticles: A Versatile Route to Metal Phosphide Nanoparticles. Chem. Commun. 2010, 46, 5578-5580. https://doi.org/10.1039/C0CC00684J.

(25) Carenco, S.; Le Goff, X. F.; Shi, J.; Roiban, L.; Ersen, O.; Boissière, C.; Sanchez, C.; Mézailles, N. Magnetic Core-Shell Nanoparticles from Nanoscale-Induced Phase Segregation. Chem. Mater. 2011, 23 (8), 2270-2277. https://doi.org/10.1021/cm200575g.

(26) Carenco, S.; Leyva-Pérez, A.; Concepción, P.; Boissière, C.; Mézailles, N.; 
Sanchez, C.; Corma, A. Nickel Phosphide Nanocatalysts for the Chemoselective Hydrogenation of Alkynes. Nano Today 2012, 7 (1), 21-28.

https://doi.org/https://doi.org/10.1016/j.nantod.2011.12.003.

(27) Carenco, S.; Boissière, C. ; Mézailles, N. ; Sanchez, C. Les Phosphures de Métaux. Une Renaissance à l'échelle Nanométrique. Actual. Chim. 2012, 362, $22-28$.

(28) Carenco, S.; Hu, Y.; Florea, I.; Ersen, O.; Boissière, C.; Mézailles, N.; Sanchez, C. Metal-Dependent Interplay between Crystallization and Phosphorus Diffusion during the Synthesis of Metal Phosphide Nanoparticles. Chem. Mater. 2012, 24 (21), 4134-4145. https://doi.org/10.1021/cm3022243.

(29) Carenco, S.; Portehault, D.; Boissière, C.; Mézailles, N.; Sanchez, C. Nanoscaled Metal Borides and Phosphides: Recent Developments and Perspectives. Chem. Rev. 2013, 113 (10), 7981-8065. https://doi.org/10.1021/cr400020d.

(30) Carenco, S.; Hu, Y.; Florea, I.; Ersen, O.; Boissière, C.; Sanchez, C.; Mézailles, N. Structural Transitions at the Nanoscale: The Example of Palladium Phosphides Synthesized from White Phosphorus. Dalt. Trans. 2013, 42 (35), 12667-12674. https://doi.org/10.1039/C3DT50686J.

(31) Carenco, S.; Portehault, D.; Boissière, C.; Mézailles, N.; Sanchez, C. 25th Anniversary Article: Exploring Nanoscaled Matter from Speciation to Phase Diagrams: Metal Phosphide Nanoparticles as a Case of Study. Adv. Mater. 2014, 26 (3), 371-390. https://doi.org/10.1002/adma.201303198.

(32) Dreyfuss, S.; Pradel, C.; Vendier, L.; Mallet-Ladeira, S.; Mézailles, N. The Role of Water in the Synthesis of Indium Nanoparticles. Chem. Commun. 2016, 52 
(99), 14250-14253. https://doi.org/10.1039/C6CC08049A.

(33) Nguyen, A.-M.; Bahri, M.; Dreyfuss, S.; Moldovan, S.; Miche, A.; Méthivier, C.; Ersen, O.; Mézailles, N.; Carenco, S. Bimetallic Phosphide (Ni,Cu)2P Nanoparticles by Inward Phosphorus Migration and Outward Copper Migration. Chem. Mater. 2019, 31 (16), 6124-6134.

https://doi.org/10.1021/acs.chemmater.9b01505.

(34) Stefanos Mourdikoudis, L. M. L.-M. Oleylamine in Nanoparticle Synthesis. Chem. Mater. 2013, 25, 1465-1476.

(35) Dechong Ma Yan Zhao, Xinli Hao, Linzhi Li, Li Zhang, Yan Lu, Chengzhong Yu, J. Z. Synthesis of Bismuth Nanoparticles and Self-Assembled Nanobelts by a Simple Aqueous Route in Basic Solution. Colloids Surfaces A Physicochem. Eng. Asp. 2012, 395, 276-283.

(36) Mao Lin Zhang Wen Xing Zhang, Xiao Wen Luan, Jian Jiang, Long Feng Li, C. F. "Synthesis of Bismuth Nanoparticles by a Simple One-Step Solvothermal Reduction Route.” Appl. Mech. Mater. 2013, 423-426, 155-158.

(37) Durand, J.; Teuma, E.; Malbosc, F.; Kihn, Y.; Gómez, M. Palladium Nanoparticles Immobilized in Ionic Liquid: An Outstanding Catalyst for the Suzuki C-C Coupling. Catal. Commun. 2008, 9, 273-275. https://doi.org/https://doi.org/10.1016/j.catcom.2007.06.015.

(38) Reina, A.; Pradel, C.; Martin, E.; Teuma, E.; Gómez, M. Palladium Nanoparticles Stabilised by Cinchona-Based Alkaloids in Glycerol: Efficient Catalysts for Surface Assisted Processes. RSC Adv. 2016, 6, 93205-93216. https://doi.org/10.1039/C6RA19230K. 
(39) Reina, A.; Favier, I.; Pradel, C.; Gómez, M. Stable Zero-Valent Nickel Nanoparticles in Glycerol: Synthesis and Applications in Selective Hydrogenations. Adv. Synth. Catal. 2018, 360, 3544-3552. https://doi.org/10.1002/adsc.201800786.

(40) Favier, I.; Massou, S.; Teuma, E.; Philippot, K.; Chaudret, B.; Gómez, M. A New and Specific Mode of Stabilization of Metallic Nanoparticles. Chem. Commun. 2008, 3296-3298. https://doi.org/10.1039/B804402C.

(41) Reina, A.; Serrano-Maldonado, A.; Teuma, E.; Martin, E.; Gómez, M. Palladium Nanocatalysts in Glycerol: Tuning the Reactivity by Effect of the Stabilizer. Catal. Commun. 2018, 104, 22-27. https://doi.org/https://doi.org/10.1016/j.catcom.2017.10.004.

(42) Dang-Bao, T.; Pradel, C.; Favier, I.; Gómez, M. Making Copper(0) Nanoparticles in Glycerol: A Straightforward Synthesis for a Multipurpose Catalyst. Adv. Synth. Catal. 2017, 359, 2832-2846. https://doi.org/10.1002/adsc.201700535.

(43) Pan, C.; Pelzer, K.; Philippot, K.; Chaudret, B.; Dassenoy, F.; Lecante, P.; Casanove, M.-J. Ligand-Stabilized Ruthenium Nanoparticles: Synthesis, Organization, and Dynamics. J. Am. Chem. Soc. 2001, 123, 7584-7593. https://doi.org/10.1021/ja003961m.

(44) Balasurya, S.; Syed, A.; Thomas, A. M.; Bahkali, A. H.; Elgorban, A. M.; Raju, L. L.; Khan, S. S. Highly Sensitive and Selective Colorimetric Detection of Arginine by Polyvinylpyrrolidone Functionalized Silver Nanoparticles. J. Mol. Liq. 2019, 112361. https://doi.org/https://doi.org/10.1016/j.molliq.2019.112361.

(45) Rahman, M. S.; Chakraborty, A.; Mazumdar, S.; Nandi, N. C.; Bhuiyan, M. N. I.; 
Alauddin, S. M.; Khan, I. A.; Hossain, M. J. Effects of Poly(Vinylpyrrolidone)

Protected Platinum Nanoparticles on Seed Germination and Growth Performance of Pisum Sativum. Nano-Structures \& Nano-Objects 2020, 21, 100408.

https://doi.org/https://doi.org/10.1016/j.nanoso.2019.100408.

(46) Favier, I.; Pla, D.; Gómez, M. Metal-Based Nanoparticles Dispersed in Glycerol: An Efficient Approach for Catalysis. Catal. Today 2018, 310, 98-106. https://doi.org/https://doi.org/10.1016/j.cattod.2017.06.026.

(47) Kovalev, A. I.; Wainstein, D. L.; Tetelbaum, D. I.; Hornig, W.; Kucherehko, Y. N. Investigation of the Electronic Structure of the Phosphorus-Doped Si and SiO2:Si Quantum Dots by XPS and HREELS Methods. Surf. Interface Anal. 2004, 36, 959-962. https://doi.org/10.1002/sia.1811.

(48) Gaskell, K.; Smith, M.; Sherwood, P. Valence Band X-Ray Photoelectron Spectroscopic Studies of Phosphorus Oxides and Phosphates. J. Vac. Sci. Technol., A 2004, 22, 1331-1336. https://doi.org/10.1116/1.1763904.

(49) Sherwood, P. M. A. Introduction to Studies of Phosphorus-Oxygen Compounds by XPS. Surf. Sci. Spectra 2002, 9 (1), 62-66. https://doi.org/10.1116/11.20030101.

(50) Bonifacio, C. S.; Carenco, S.; Wu, C. H.; House, S. D.; Bluhm, H.; Yang, J. C. Thermal Stability of Core-Shell Nanoparticles: A Combined in Situ Study by XPS and TEM. Chem. Mater. 2015, 27, 6960-6968. https://doi.org/10.1021/acs.chemmater.5b01862.

(51) Bytchkov, A.; Fayon, F.; Massiot, D.; Hennet, L.; Price, D. L. 31P Solid-State NMR Studies of the Short-Range Order in Phosphorus-Selenium Glasses. Phys. 
Chem. Chem. Phys. 2010, 12, 1535-1542. https://doi.org/10.1039/B919118F.

(52) Virieux, H.; Le Troedec, M.; Cros-Gagneux, A.; Ojo, W.-S.; Delpech, F.; Nayral, C.; Martinez, H.; Chaudret, B. InP/ZnS Nanocrystals: Coupling NMR and XPS for Fine Surface and Interface Description. J. Am. Chem. Soc. 2012, 134, 1970119708. https://doi.org/10.1021/ja307124m.

(53) Hamaed, H.; Laschuk, M. W.; Terskikh, V. V; Schurko, R. W. Application of Solid-State 209Bi NMR to the Structural Characterization of Bismuth-Containing Materials. J. Am. Chem. Soc. 2009, 131, 8271-8279. https://doi.org/10.1021/ja901347k.

(54) von Hänisch, C.; Nikolova, D. Synthesis and Characterisation of Molecular Bismuth Phosphorus Compounds Containing Bi2 Units with Bi-Bi Single and Double Bonds. Eur. J. Inorg. Chem. 2006, 2006 (23), 4770-4773. https://doi.org/10.1002/ejic.200600474.

(55) Andrew J. Pell, Guido Pintacuda, C. P. G. Paramagnetic NMR in Solution and the Solid State. Prog. Nucl. Magn. Reson. Spectrosc. 2019, 111, 1-271. https://doi.org/https://doi.org/10.1016/j.pnmrs.2018.05.001.

(56) De Trizio, L.; Figuerola, A.; Manna, L.; Genovese, A.; George, C.; Brescia, R.; Saghi, Z.; Simonutti, R.; Van Huis, M.; Falqui, A. Size-Tunable, Hexagonal Plate-like $\mathrm{Cu} 3 \mathrm{P}$ and Janus-like $\mathrm{Cu}-\mathrm{Cu} 3 \mathrm{P}$ Nanocrystals. ACS Nano 2012, 6 (1), 32-41. https://doi.org/10.1021/nn203702r.

(57) Li, T.; Senesi, A. J.; Lee, B. Small Angle X-Ray Scattering for Nanoparticle Research. Chem. Rev. 2016, 116, 11128-11180. https://doi.org/10.1021/acs.chemrev.5b00690. 
(58) Demange, M.; Le Goff, X.-F.; Le Floch, P.; Mézailles, N. P4 Activation with Pt0 Metal Centers: Selective Formation of a Dinuclear $\{\mathrm{Pt} 2(\mu, \mathrm{H} 2: 2-\mathrm{P} 2)\}$ Complex. Chem. - A Eur. J. 2010, 16, 12064-12068.

https://doi.org/10.1002/chem.201000894.

(59) Li, J.; Ni, Y.; Liao, K.; Hong, J. Hydrothermal Synthesis of Ni12P5 Hollow Microspheres, Characterization and Photocatalytic Degradation Property. $J$. Colloid Interface Sci. 2009, 332, 231-236.

https://doi.org/https://doi.org/10.1016/j.jcis.2008.12.058.

(60) Baquero, E. A.; Ojo, W.-S.; Coppel, Y.; Chaudret, B.; Urbaszek, B.; Nayral, C.; Delpech, F. Identifying Short Surface Ligands on Metal Phosphide Quantum Dots. Phys. Chem. Chem. Phys. 2016, 18, 17330-17334. https://doi.org/10.1039/C6CP03564G. 
Graphic for Table of Content

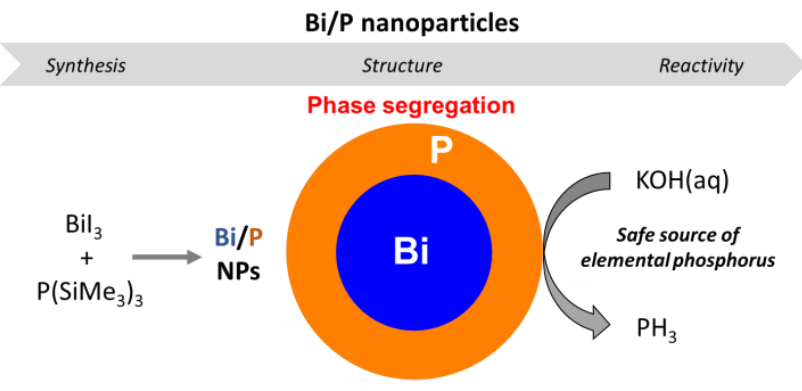

